\title{
Rectus sheath hematoma in a macrosomic neonate following difficult delivery. Case report
}

\author{
Suzan Gunduz ${ }^{a}$, M.D., Semra Kara ${ }^{b}$, M.D., Ayşe Aktas ${ }^{c}$, M.D., Abdulkadir Eren ${ }^{b}$, M.D. and Vedat Bakan ${ }^{d}$, M.D.
}

\begin{abstract}
Macrosomia is a risk factor for birth injuries and is associated with neonatal morbidity and mortality. Cephalohematoma and clavicular fracture are the most frequent birth injuries. Intraabdominal injuries are uncommon birth injuries. Rectus sheath hematoma (RSH) is an accumulation of blood in the sheath of rectus abdominis muscle. It is associated with trauma, operations and anticoagulant therapy, especially in adults and elders. We present a macrosomic male neonate with difficult vaginal delivery, who had in the physical examination periumblical ecchymose of $1 \times 1 \mathrm{~cm}$ and a parietal cephalohametoma of $1 \times 1 \mathrm{~cm}$. The abdominal ultrasonogram and the computed tomography scan of the abdomen showed a $7 \times 4 \times 2 \mathrm{~cm}$ right rectus sheath hematoma.

Key words: rectus sheath hematoma, macrosomia fetal, birth injury, neonates.
\end{abstract}

http:/ / dx.doi.org/10.5546/ aap.2018.e82

To cite: Gunduz S, Kara S, Aktas A, et al.Rectus sheath hematoma in a macrosomic neonate following difficult delivery. Case report. Arch Argent Pediatr 2018;116(1):e82-e84.

\section{INTRODUCTION}

Birth injuries are a significant cause of neonatal morbidity and mortality. Factors that increase the risk of birth injuries include macrosomia (fetal weight greater than $4000 \mathrm{~g}$ ), maternal obesity, breech presentation, operative vaginal delivery (ie, the use of forceps or vacuum during delivery), small maternal size, and the presence of maternal pelvic anomalies. The

a. Turgut Ozal University, Department of Pediatrics, Ankara, Turkey

b. Turgut Ozal University, Department of Pediatrics, Division of Neonatalogy, Ankara, Turkey

c. Turgut Ozal University, Department of Radiology, Ankara, Turkey

d. Turgut Ozal University, Department of Pediatric Surgery, Ankara, Turkey.

E-mail address:

Suzan Gunduz, M.D.: akinsuzan@gmail.com

Funding: None.

Conflict of interest: None.

Received: 1-7-2016

Accepted: 7-12-2017 overall incidence of birth injuries is about 2 and 1.1 percent in singleton vaginal and cesarean deliveries, respectively. Intra-abdominal birth trauma is uncommon and primarily consists of rupture or subcapsular hemorrhage into the liver, spleen, and adrenal gland. ${ }^{1}$

Rectus sheath hematoma (RSH) is the accumulation of blood in the sheath of rectus abdominis muscle and it can develop owing to direct damage to the muscle itself or tearing in one of the superior or inferior epigastric vessels that run along its posterior aspect. The etiology includes trauma, operations, subcutaneous drug injections, anticoagulant therapy, hematological diseases, hypertension, coughing, physical exercise and pregnancy; it rarely occurs spontaneously. Rectus sheath hematoma is a rarely seen but important disease causing abdominal pain in adults. ${ }^{2}$

We reported a macrosomic neonate with rectus sheath hematoma following difficult delivery.

\section{Case report}

A $4530 \mathrm{~g}$ male infant was born at 40 weeks' gestation to a 25-year-old gravida 2 para 2 mother with vaginal delivery; the Apgar scores were at first and 5th minutes 7 and 9, respectively. It was a difficult delivery; extraction maneuvers were performed, but forceps or vacuum were not used. The mother had no coagulopathy in tests and she was not receiving any anticoagulants. Physical examination just after delivery revealed a periumblical ecchymose of $1 \times 1 \mathrm{~cm}$ and a cephalohematoma of $1 \times 1 \mathrm{~cm}$ on his parietooccipital area. At 3 hours of life the hemoglobin level was $13.6 \mathrm{~g} / \mathrm{dL}$, hematocrit $41 \%$, platelet $191000 / \mathrm{UL}$, activated partial tromboplastin time (aPTT) $27.5 \mathrm{sec}$, prothrombin time (PT) $15.7 \mathrm{sec}$, international normalized ratio (INR) 1.23 and total bilirubin $8.9 \mathrm{mg} / \mathrm{dl}$. The other biochemical tests were normal. An abdominal ultrasonogram showed a $66 \times 16 \mathrm{~mm}$ mass with fluid levels between umblicus and inferior sternum, and it displaced left and right liver lobes to posterior (Figure 1). A follow-up computed tomography (CT) scan of the abdomen showed a 
$7 \times 4 \times 2 \mathrm{~cm}$ right rectus sheath hematoma (Figure 2).

A superficial tissue ultrasonogram showed a 9x9 mm cephalohematoma on the parietooccipital area. Complete blood cell count examination on the 24th hour and 36th hour of admission revealed hemoglobin values of $12.4 \mathrm{~g} / \mathrm{dl}$ and $14.3 \mathrm{~g} / \mathrm{dl}$, respectively, while total bilirubin levels were at $10.2 \mathrm{mg} / \mathrm{dl}$ and $10.8 \mathrm{mg} / \mathrm{dl}$, respectively. Breastfeeding was iniciated after birth and no other treatment was required. We follow-up the patient frequently by physical examination, complete blood count and bilirubin levels without abnormal findings. He discharged home on his 5 th day. He is 5 months old and has no pathology in his physical examination and abdominal ultrasonogram.

\section{DISCUSSION}

Rate of birth trauma is about $2 \%$ in normal vaginal delivery with cephalic presentation and

FIGURE 1. Gray-scale US shows hypoechoic hematoma located in front of the left lobe of liver (between cursors)

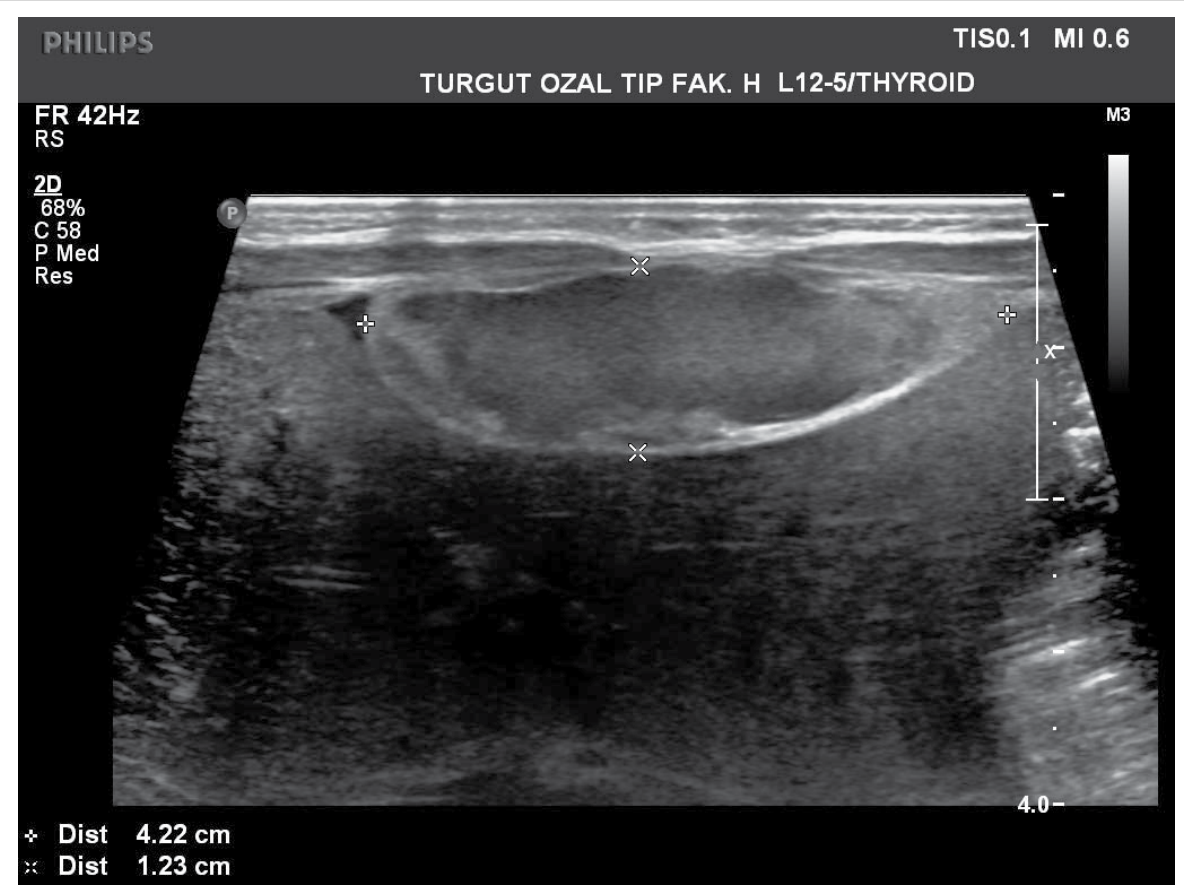

FIGURE 2. Axial and coronal CT scan of the abdomen show hematoma of rectus sheath

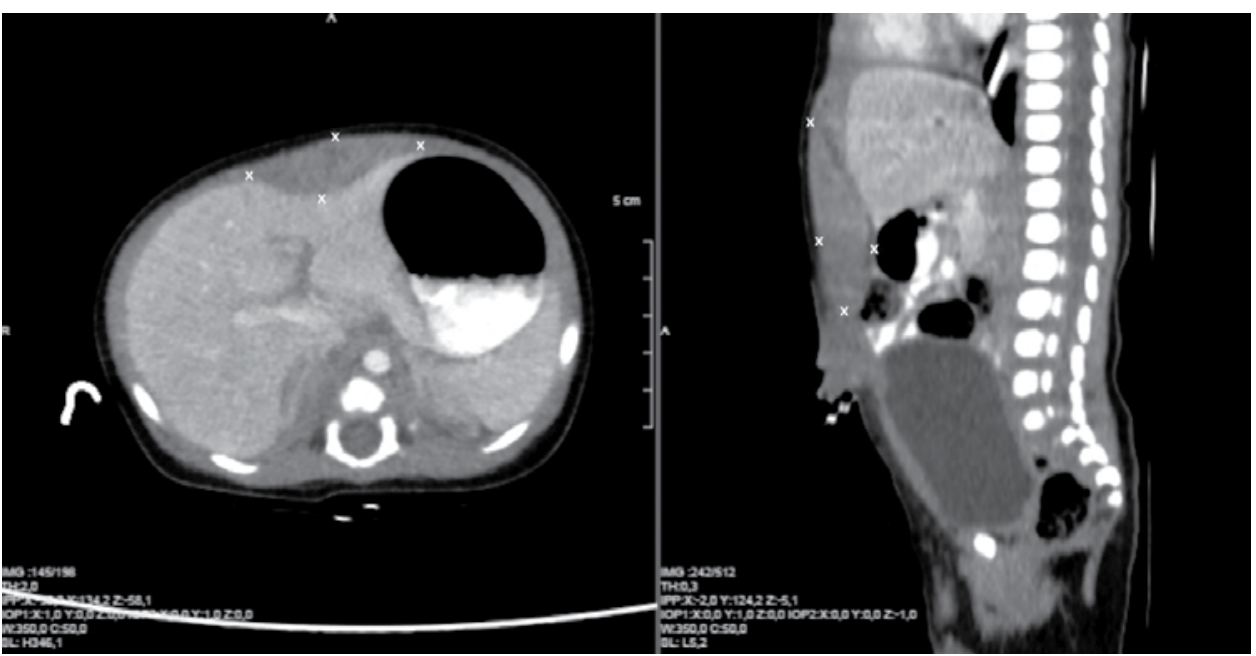


$1.1 \%$ in cesarean section. ${ }^{3}$ Birth injuries include soft tissue injuries (bruises, petechiae, subcutaneous fat necrosis, ulceration, and perforation), cephalohematoma, caput succedaneum, spontaneous intracranial hemorrhage, spinal cord injury, brachial plexus injury (Erb's palsy and Klumpke's paralysis), facial nerve palsy, musculoskeletal injury (clavicular fracture and torticollis), and hypoxic-ischemic injury. ${ }^{4}$ In most studies cephalohematoma and clavicular fracture were the most frequent birth injuries. ${ }^{5}$ The incidence of birth injuries has declined with improvements in obstetrical care and prenatal diagnosis. However macrosomia is an important risk factor of birth injury; intra-abdominal birth trauma is uncommon. ${ }^{1}$ Ultrasonography is the best modality to diagnose intra-abdominal birth injuries and can be performed at the bedside. Computed tomography can also provide useful diagnostic information.

The patient must be observed in regards of possible complications such as jaundice, hypovolemia, hypovolemic shock and the possible treatments for each condition. $\mathrm{RSH}$ treatment could be conservative or invasive. Treatment choice is determined by the patient's condition. Main therapy is conservative management. Conservative treatment consists of rest, analgesia, management of predisposing factors, compression of hematoma, ice treatment and if needed reversal of anticoagulation, volume expansion or blood transfusion, and phototherapy for jaundice. ${ }^{1}$ Invasive hemorrhage control of RSH should be considered in patients hemodynamically unstable that don't respond to volume expansion, with enlarging hematomas, patients that show severe peritoneal irritation or signs of abdominal compartment syndrome. ${ }^{6}$

We follow-up this neonate, breastfeeding was initiated after birth and neither conservative nor invasive management was required.

However RSH is associated with trauma, operations, subcutaneous drug injections and anticoagulant therapy in elders we did not encounter any neonatal case in the literature. ${ }^{7,8}$

To the best of our knowlegde this is the first case of RSH in an injured macrosomic neonate. We aimed to present this case for emphasising RSH as a birth injury in a macrosomic baby. Health care providers especially caring for newborns must keep in mind this rare injury in macrosomic neonates.

\section{REFERENCES:}

1. Uhing MR Management of birth injuries. Pediatr Clin North Am 2004;51(4):1169-86.

2. Hatjipetrou A, Anyfantakis D, Kastanakis M. Rectus sheath hematoma: a review of the literature. Int J Surg 2015;13: 267-71.

3. Demissie K, Rhoads GG, Smulian JC, et al. Operative vaginal delivery and neonatal and infant adverse outcomes: population based retrospective analysis. BMJ 2004;329(7456):24-9

4. Boulet SL, Alexander GR, Salihu HM, et al. Macrosomic births in the united states: determinants, outcomes, and proposed grades of risk. Am J Obstet Gynecol 2003;188(5):1372-8.

5. Warke C, Malik S, Chokhandre M, et al. Birth InjuriesA Review of Incidence, Perinatal Risk Factors and Outcome. Bombay Hosp J 2012;54(2):202-8.

6. Jafferbhoy SF, Rustum Q, Shiwani MH. Abdominal compartment syndrome: a fatal complication from a rectus sheath haematoma. BMJ Case Rep 2012;2012:bcr 1220115332.

7. MaharajD, Ramdass M, Teelucksingh S, et al. Rectus sheath haematoma: a new set of diagnostic features. Postgrad Med J 2002;78(926):755-6.

8. Fitzgerald JE, Fitzgerald LA, Anderson FE, et al. The changing nature of rectus sheath haematoma: case series and literature review. Int J Surg 2009;7(2):150-4. 